\title{
Retención de orina en un paciente inmunocompetente: mielitis transversa aguda
}

\section{Urinary retention in immunocompetent patient: acute transverse myelitis}

\author{
M.V. Villaverde ${ }^{4}$, C. López Canales², F. Gutiérrez Moreno² ${ }^{2}$ A. Martínez Hernández ${ }^{3}$, \\ P. Vela ${ }^{1}$
}

\section{RESUMEN}

Bajo el término de mielitis transversa aguda (MTA) se engloba un grupo heterogéneo de enfermedades con el nexo común de producir una lesión focal inflamatoria de la médula espinal de instauración brusca.

El conocimiento de la MTA se está viendo modificado constantemente con el advenimiento de nuevas técnicas diagnósticas y teorías sobre su origen inmunológico.

La responsabilidad de realizar un diagnóstico precoz, recae principalmente en el ámbito de la Atención Primaria y debe fundamentarse siempre en la realización de una detallada historia clínica asociada a una exploración neurológica minuciosa. El correcto manejo de la situación clínica una vez detectada, precisará de una derivación urgente al hospital de referencia, para ser evaluado y tratado de forma temprana por equipos multidisciplinares.

Es de vital importancia la intervención precoz en muchas de estas patologías, ya que mejora el pronóstico de estos pacientes y disminuye considerablemente las secuelas.

Palabras clave. Mielitis transversa. Diagnóstico. Mielopatía aguda.

\begin{abstract}
A heterogeneous group of diseases is included under the term acute transverse myelitis (ATM); these have the common factor of producing an inflammatory focal injury of the spinal cord in an acute form.

Understanding of ATM is being constantly improved with the arrival of new diagnostic techniques and theories about its immune origin.

Responsibility for making an early diagnosis lies primarily in the field of primary care and must always be based on the completion of a detailed clinical report together with a thorough neurological examination. Once detected, correct handling of the clinical situation will require an urgent referral to a hospital for evaluation and treatment at an early stage by multidisciplinary teams.

Early intervention in many of these diseases is vital, because it improves the prognosis of these patients and significantly reduces injuries.
\end{abstract}

Key words. Transverse myelitis. Diagnosis. Acute myelopathy.
1. Unidad Docente Med. Familiar y Comunitaria. Sector Zaragoza III. Servicio Aragonés de Salud.

2. Centro de Salud Bombarda. Sector Zaragoza III.

3. Servicio de Urgencias. Hospital de Calahorra. La Rioja.

Recepción: 28 de junio de 2011

Aceptación provisional: 6 de septiembre de 2011

Aceptación definitiva: 15 de septiembre de 2011

\author{
Correspondencia: \\ María Victoria Villaverde-Royo \\ Unidad Docente Medicina Familiar y \\ Comunitaria \\ Centro de Salud José Ramón Muñoz \\ Paseo Sagasta, 52 \\ 50006 Zaragoza \\ E-mail: vickyvillaverde@hotmail.com
}




\section{INTRODUCCIÓN}

Bajo el término de mielitis transversa aguda (MTA) se engloba un grupo heterogéneo de enfermedades que tienen en común producir una lesión focal inflamatoria de la médula espinal de instauración brusca. La inflamación, el edema y la necrosis en uno o varios segmentos medulares producen una alteración de la función motora, sensitiva o autonómica ${ }^{1}$. Se trata de una entidad rara, que puede afectar a cualquier edad, su incidencia se estima en 1,34 casos por cada millón de habitantes al año y varía en función del grupo etáreo, siendo mayor en pacientes inmunocomprometidos ${ }^{2,3}$.

El conocimiento de la MTA se ha visto modificado constantemente con el advenimiento de nuevas técnicas diagnósticas y teorías sobre su origen inmunológico.

\section{CASO CLÍNICO}

Se presenta el caso de una mujer de 27 años de nacionalidad china, que no comprendía castellano, sin alergias medicamentosas conocidas, ni antecedentes médico-quirúrgicos de interés y correctamente vacunada durante la infancia en su país de origen. La paciente acudió por primera vez a urgencias del centro de salud por una reacción urticariforme pruriginosa de veinticuatro horas de evolución. En esta primera consulta se le pautó un antihistamínico intramuscular y corticoide de liberación retardada siendo diagnosticada de urticaria.

Un día más tarde la paciente acude de nuevo a urgencias por presentar aumento de las lesiones, refiriendo intenso picor en cara, cuero cabelludo, tronco, extremidades superiores y genitales. Se observan varias lesiones polimorfas de distribución dispersa generalizada, con lesiones costrosas hemorrágicas y otras vesículopustulosas de dos a cinco milímetros de diámetro, alguna de ellas umbilicadas en zona central. En la región centro-abdominal presenta lesión costrosa necrótica que la paciente refiere haber manipulado. Tras la exploración, fue diagnosticada de varicela. Se procedió a descartar complicaciones mediante auscultación y petición de radiografía de tórax que resultó completamente normal, por lo que tras la toma de frotis de lesiones fue derivada a su domicilio explicándole las medidas de aislamiento respiratorio que era conveniente tomar con sus convivientes no inmunizados. Se pautó aciclovir oral $800 \mathrm{mg}$ cada cuatro horas, cinco veces al día, con descanso nocturno siete días y antihistamínicos.
A los siete días, nuestra paciente acudió al servicio de Urgencias de nuestro hospital de referencia por astenia intensa de 24 horas de evolución sin otra sintomatología. La exploración fue completamente normal, por lo que ante la ausencia de alteraciones tanto analíticas como radiológicas se decidió el alta domiciliaria.

A las doce horas, acude de nuevo a urgencias por dolor suprapúbico y astenia. En la anamnesis refiere disuria de dos días de evolución así como oligoanuria, sin proceso febril concomitante. La auscultación cardiopulmonar fue totalmente normal. La exploración abdominal presentó dolor a nivel suprapúbico palpándose globo vesical con sucusión positiva en ambas fosas renales. Ante la sospecha de retención aguda de orina se procedió a realizar un sondaje vesical comprobando un vaciamiento de $1.200 \mathrm{cc}$. Se realizaron analíticas sanguíneas y de orina con resultados dentro de los parámetros normales. En la radiografía de abdomen practicada destacaba la presencia de abundantes restos fecales retenidos.

Durante su reevaluación en la sala de observación, el acompañante-traductor refiere una clara mejoría del dolor abdominal y expresa que la paciente aquejaba pérdida de fuerza y debilidad progresiva de extremidades inferiores desde hacía cuatro días. Se le reevalúa destacando rigidez cervical marcada, pares craneales normales, balance motor $5 / 5$ distal y proximal en extremidades superiores. En extremidades inferiores aparición de una para-paresia flácida con balance motor $3 / 5$ proximal y $4 / 5$ distal. Reflejos osteotendinosos con hiporreflexia rotuliana bilateral y abolición de reflejos aquíleos. Reflejo cutáneo plantar en flexión bilateral. Hipo-sensibilidad en metámeras por debajo de D5 (mama).

Ante la presencia de alteraciones neurológicas se le indicó la realización de una tomografía axial computarizada (TAC) craneoencefálica donde no se apreciaron lesiones focales intracraneales y los espacios de líquido cefalorraquídeo, así como la diferenciación de sustancia gris y sustancia blanca fueron normales.

Posteriormente, se le realizó punción lumbar donde se apreció líquido claro y se cursaron muestras para estudio de laboratorio ingresando en el servicio de Neurología con el diagnóstico de sospecha de mielitis transversa incompleta postinfecciosa.

Durante su ingreso se le realizó una resonancia nuclear magnética (RNM) medular, donde se apreció un área de hiperseñal en T2 localizada a nivel del cordón medular cervical (C5-D1) con una pequeña dilatación del conducto ependimario, muy probablemente relacionada con mielopatía infecciosa. La lesión mostró leve hipointensidad en T1. Todo ello ratificó el diagnóstico de mielitis infecciosa en cordón medular cervical (Fig. 1). 

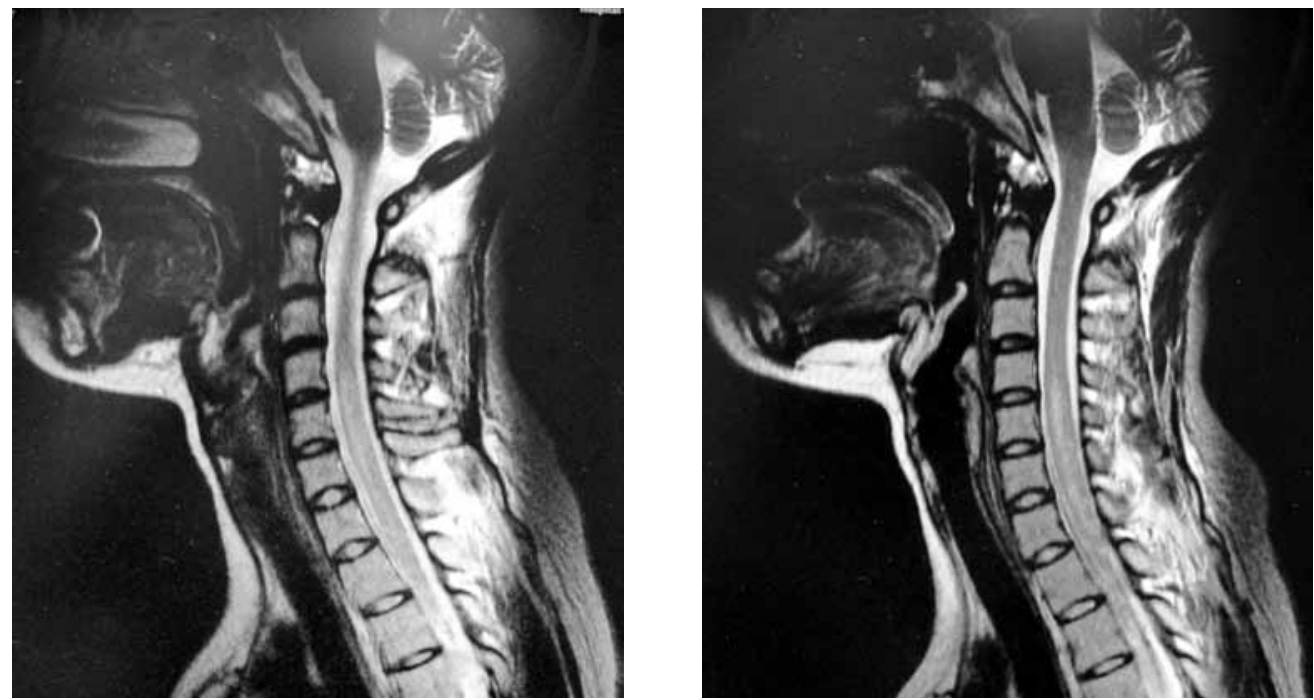

Figura 1. Mielitis infecciosa en cordón medular (C5-D1): área de hiperseñal en T2 localizada a nivel del cordón medular cervical (C5-D1) con una pequeña dilatación del conducto ependimario, leve hipointensidad en T1.

Los resultados de la serología de LCR para Borrelia, Brucella, sífilis, virus de Epstein Barr (VEB), Citomegalovirus (CMV), virus Herpes simple (VHS) y virus Varicela zóster (VVZ) fueron negativos. Los resultados de la serología en suero fueron congruentes con los de LCR, excepto para virus Varicela zóster que resultó positiva. Se pidió también serología Virus Inmunodeficiencia Humano con resultado negativo. Por lo que su diagnóstico etiológico de alta probabilidad fue de mielitis aguda por infección virus Varicela zóster (VVZ).

Desde su ingreso ante la alta sospecha de mielitis aguda por VVZ, se inició tratamiento con aciclovir i.v. durante los primeros diez días asociando corticoide i.v.

La paciente experimentó una lenta aunque constante mejoría, finalmente y tras un mes de ingreso, se le retiró la sonda sin presentar en los días posteriores ningún episodio de retención aguda de orina. Al alta continuó tratamiento rehabilitador.

\section{DISCUSIÓN}

El diagnóstico de mielopatía MTA requiere demostrar que existe inflamación de la médula espinal. Los algoritmos diagnósticos basados en consenso de expertos, así como la única guía de práctica clínica sobre pruebas radiológicas en que se trata esta entidad ${ }^{4}$, recomiendan hacer punción lumbar, resonancia magnética con gadolinio y serologías para virus y bacterias ${ }^{5,6}$. En el TAC no se recomienda dada su baja sensibilidad.

La etiología de la MTA se asocia principalmente a procesos autoinmunes, tanto sistémicos, como localizados en el sistema nervioso central afectando a las vainas de mielina $^{7,8}$. Otros procesos causantes son los de origen infeccioso, que provocan una agresión directa en la médula espinal. Son muchos los microorganismos sobre los que existen casos publicados: dengue, parotiditis, sarampión, rubeóla, virus Hepatitis $C$, B y E, CMV, VEB, VVZ, Coxackie, Influenza, $V H S$, micobacterias, Mycoplasma pneumoniae, sífilis, Listeria o Borrelia ${ }^{9,10}$.

En un número no desdeñable de ocasiones resulta complejo discernir su patogenia ya que los cuadros infecciosos o incluso las vacunaciones (difteria, tétanos, rubéola, hepatitis $\mathrm{B}$, rabia, Bordetella pertussis, cólera, tifus, poliomielitis) pueden ocasionar una brusca reacción inmune que es la que finalmente produce la necrosis de la sustancia gris o la lesión de la sustancia blanca, con desmielinización perivenosa e infiltrados linfocitarios ${ }^{11}$. 
Recientemente han aumentado las publicaciones de etiología autoinmunitaria ligadas al desarrollo de las nuevas técnicas diagnósticas. Están descritos también casos asociados a neoplasias, inyecciones de heroína y los tratamientos con radioterapia. No obstante, son todavía muchos los casos que quedan clasificados como de origen idiopático ${ }^{12}$.

En cuanto a la clínica, es importante destacar que son pocos los síntomas guía que deben de llevarnos a su sospecha. Un tercio de los pacientes refieren el antecedente de enfermedad aguda infecciosa reciente. La retención urinaria es otro de los síntomas iniciales, seguidos de parestesias progresivamente ascendentes, dolor súbito e intenso de la zona afecta y debilidad progresiva de miembros inferiores ${ }^{13}$.

La evolución de la paciente fue favorable, encontrándose dentro del $50 \%$ que evolucionan hacia la recuperación total o casi total en el primer mes. No obstante, hasta un $25 \%$ de los pacientes, arrastrarán déficits permanentes, considerándose compleja su recuperación si ésta no se inicia en los primeros tres meses tras el comienzo del tratamiento. Es por ello de vital importancia realizar un abordaje precoz, sobre todo en aquellos casos de origen infeccioso o autoinmune donde los tratamientos inmunomoduladores o antiinfecciosos han demostrado su eficacia ${ }^{14}$. La responsabilidad de realizar un diagnóstico precoz sobre este tipo de patologías poco frecuentes, recae principalmente en el ámbito de la Atención Primaria y deben fundamentarse siempre en la realización de una detallada historia clínica, asociada a una exploración neurológica minuciosa.

El correcto manejo de la situación clínica, precisará de una derivación urgente al hospital de referencia, para ser evaluado y tratado de forma temprana por equipos multidisciplinares. La intervención precoz en muchas de estas patologías, mejora el pronóstico y disminuye considerablemente las secuelas.

\section{BIBLIOGRAFÍA}

1. Transverse Myelitis Consortium Working Group. Proposed diagnostic criteria and no- sology of acute transverse myelitis. Neurology 2002; 59: 499-505.

2. Scotti G, Gerevini S. Diagnosis and differential diagnosis of acute transverse myelopathy. The role of neuroradiological investigations and review of the literature. Neurol Sci 2001; 22: 69-73.

3. Oñate Vergara E, Sota Busselo I, García-Santiago J, Gaztañaga Expósito R, Nogués Pérez A, Ruiz BEnITo MA. Transverse myelitis in immunocompetent children. An Pediatr (Barc) 2004; 61: 177-180.

4. Seidenwurm DJ, Wippold FJ II, Brunberg JA, CorNelius RS, Davis PC, De la Paz RL et al. ACR Appropriateness Criteria ${ }^{\circledR}$ myelopathy. [online publication]. Reston (VA): American College of Radiology (ACR); 2008 [acceso 20 de julio de 2011]. En: http://www.guideline.gov/content.aspx?id $=13672 \&$ search $=$ myelitis + transv erse\#Section 424

5. Gómez-ArgüElles JM, SÁnchEZ-Solla A, LóPEZDolado E, Díez-De la Lastra E, Florensa J. Acute transverse myelitis: a clinical review and algorithm for diagnostic intervention. Rev Neurol 2009; 49: 533-540.

6. Frohman EM, Wingerchuk DM. Clinical practice. Transverse myelitis. N Engl J Med 2010; 363: 564-572.

7. JEFFERY DR, MANDLER RN, DACIS LE. Transverse myelitis: Retrospective analysis of 33 cases, whit differentiatioin of cases associated with multiple sclerosis and parinfectious events. Arch Neurol 1993; 50: 532-535.

8. Polgár A, Rózsa C, Müller V, Matolcsi J, Poór G, KIss EV. Devic's syndrome and SLE: challenges in diagnosis and therapeutic possibilities based on two overlapping cases. Autoimmun Rev 2011; 10: 171-174.

9. De Carli DM, Pannebeker J, Pedro Fl, Haygert CJ, Hertz E, Beck Mde O. Transverse myelitis associated to HCV infection. Braz J Infect Dis 2009; 13: 147-152.

10. Chanthamat N, Sathirapanya P. Acute transverse myelitis associated with dengue viral infection. J Spinal Cord Med 2010; 33: 425-427.

11. Tezzon F, Tomelleri P, Ferrari G, Segi A. Acute radiculomyelitis after antitetanus vaccination. Ital Neurol Sci 1994; 15: 191-193.

12. Alper G, Petropoulou KA, Fitz CR, Kim Y. Idiopathic acute transverse myelitis in children: an analysis and discussion of MRI findings. Mult Scler 2011; 17:74-80.

13. Elliot M, Forman MD, Dean M, Wingerchuk MD. Transverse Myelitis. N Eng J Med 2010; 363: 564-572.

14. Ong OL, Churchyard AC, New PW. The importance of early diagnosis of herpes zoster myelitis. Med J Aust 2010; 193: 546-547. 